\title{
Sustained Chemosensory Dysfunction during the COVID-19 Pandemic
}

\author{
Janne Schwab ${ }^{a, b} \quad$ Caroline Damsgaard Jensen ${ }^{a, b}$ \\ Alexander Wieck Fjaeldstad ${ }^{a, b, c}$ \\ aFlavour Clinic, Department of Otorhinolaryngology, Hospital Unit West, Central Region Denmark, Holstebro, \\ Denmark; ${ }^{b}$ Flavour Institute, Aarhus University, Aarhus, Denmark; ${ }^{c}$ Center for Eudaimonia and Human Flourishing, \\ University of Oxford, Oxford, UK
}

\section{Keywords}

COVID-19 $\cdot$ Chemosensory loss $\cdot$ Smell $\cdot$ Taste $\cdot$ Prognosis

\begin{abstract}
Introduction: Chemosensory dysfunction (CD) has proven valuable in prediction of COVID-19, as it is a frequent and specific symptom of the disease. The aim of this study was to investigate the duration of CD in patients with sudden subjective olfactory and/or gustatory loss during the SARSCoV-2 pandemic. The secondary aim was to identify possible prognostic factors for the duration of CD. Methods: An online baseline questionnaire was designed to assess subjective CD. Three rounds of follow-up questionnaires were sent out to any participants with persistent CD in 6-week intervals, prospectively assessing subjective chemosensory function and extending the follow-up time of this cohort significantly. Results: In total, 467 participants completed the baseline questionnaire. The most significant improvement and recovery of chemosensory function was observed within the first month after the initial loss. Rates became stagnant after about 2 months, and only little improvement and recovery was seen after 2-4 months. After a mean follow-up of 95.9 days (olfactory dysfunction) and 94.0 days (gustatory dysfunction), $86.7 \%$ of participants reported gustatory improvement and $82.6 \%$ reported olfactory improvement, while $55.0 \%$ reported full gustatory recovery and $43.8 \%$ re-
\end{abstract}

karger@karger.com
www.karger.com/orl

(c) 2021 S. Karger AG, Basel

Karger $\stackrel{2}{=}$ ported full olfactory recovery. Female gender was associated with better improvement of gustatory function. High subjective severity of chemosensory loss was associated with lower rates of olfactory and gustatory recovery as well as improvement of olfactory function. Young age was not associated with a better prognosis. Discussion/Conclusion: Rates of improvement and recovery of chemosensory function decreased after 2-4 months after initial chemosensory loss, possibly indicating that prolonged and perhaps permanent chemosensory loss may be a complication of SARS-CoV-2 infections. High subjective severity of $C D$ may worsen the prognosis for improvement and recovery of chemosensory function.

(c) 2021 S. Karger AG, Basel

\section{Introduction}

The newest member of the Coronaviridae family, SARS-CoV-2, has in the wake of the COVID-19 pandemic become the center of attention in media, politics, and fields of medicine. As an airborne virus with the ability to survive on surfaces for hours to days [1], the spread of SARS-CoV-2 has proven notoriously difficult to control in spite of comprehensive efforts in most countries. Besides behavioral regulation, social precautions, and the use of personal protective equipment, early and effective 
Table 1. Demographics and subjective chemosensory function

\begin{tabular}{lc}
\hline Age, mean (IQR), years & $43.6(32-53)$ \\
Sex (male/female) & $119 / 348$ \\
Smoking (former/present) & $113 / 36$ \\
Subjective olfactory function before loss (VAS 0-100), median (IQR) & $92(81-100)$ \\
Subjective olfactory function after loss (VAS 0-100), median (IQR) & $3(0-15)$ \\
Subjective gustatory function before loss (VAS 0-100), median (IQR) & $90(82-100)$ \\
Subjective gustatory function after loss (VAS 0-100), median (IQR) & $10.5(1-28)$
\end{tabular}

IQR, interquartile range; VAS, visual analog scale.

identification of the infected is crucial in mitigating the spread. The World Health Organization has pinpointed viral testing as a key component for successful prevention of COVID-19 [2]. This has emphasized the need for optimizing test strategies and identification of symptoms in order to augment the effect of available SARS-CoV-2 test resources.

Surprisingly, the chemosensory senses have proven to outmatch all other symptoms in the prediction of COVID-19 [3, 4]. Chemosensory dysfunction (CD, including anosmia, hyposmia, ageusia, and hypogeusia) occurs in a large proportion of COVID-19 patients. Two meta-analyses found pooled prevalence of olfactory dysfunction of $41.0-61.0 \%$ and gustatory dysfunction of $38.2-49.0 \%$ in COVID-19 patients $[5,6]$. Some studies have reported a prevalence of CD in up to $88 \%$ of COVID-19-positive patients [7].

A recent study that objectively measured the patients' chemosensory function using the Connecticut Chemosensory Clinical Research Center orthonasal olfaction test (in hospitalized patients) and a newly evaluated selfadministered test (home-quarantined patients) [8] found a prevalence of objective $\mathrm{CD}$ in $84.8 \%$ of the patients within 4 days of disease onset [9]. When testing for the presence of antibodies against SARS-CoV-2 in the blood of individuals who have reported CD, 1 study found that $78 \%$ of patients had antibodies in the blood [10].

Although olfactory dysfunction is the predominant $\mathrm{CD}$, it frequently occurs in combination with impaired taste and to some extent chemesthesis [11]. This has resulted in the inclusion of sudden $\mathrm{CD}$ as a recognized symptom of COVID-19 [12] and actions to include smell tests as a screening for COVID-19 [3].

While the connection between COVID-19 and CD is well established [3], a more tenacious concern has surfaced for many patients after recovery from other COVID-19 symptoms: when will I regain my sense of taste and smell? In late March 2020, the UK-based charity AbScent launched the Facebook group "COVID-19 Smell and Taste Loss." Due to a deluge of members with persistent $\mathrm{CD}$, this group exceeded 9,000 members in early October 2020. Recent studies indicate that both subjective and objectively measured chemosensory function can be affected several weeks after recovery from other COVID-19 symptoms $[9,13-16]$.

In patients with post-viral dysosmia prior to the COVID-19 era, olfactory function has been shown to improve in one-third of the patients over the course of 1 year [17]. However, this study was conducted in a specialized taste and smell clinic and as such represents the outcome of patients who have already suffered from dysosmia for several months.

While some studies indicate a high proportion of patients with an early recovery of the chemosensory function after 1 week [18], other studies indicate a gloomier prognosis for patients with a follow-up time of up to 10 weeks [9, 13-16]. Studies with longer follow-up times are warranted to gain insights into the prognosis of COVID19 -associated CD, as this can have substantial impact on both the patients recovering from COVID-19 and the requirements of health-care systems to support complete recovery of patients.

The aim of the current study was to investigate the duration of $C D$ in patients with sudden-onset $C D$ during the SARS-CoV-2 pandemic. Furthermore, the secondary aim was to identify possible prognostic factors for the duration of CD.

\section{Materials and Methods}

An online baseline questionnaire was designed in REDCap [19] and distributed online on social media, through national radio, national television, and on flyers in waiting rooms of general practitioners and hospital outpatient clinics. Patients were eligible for filling out the survey if they were above the age of 18 and had experienced a sudden CD after February 27, 2020, when the first case 


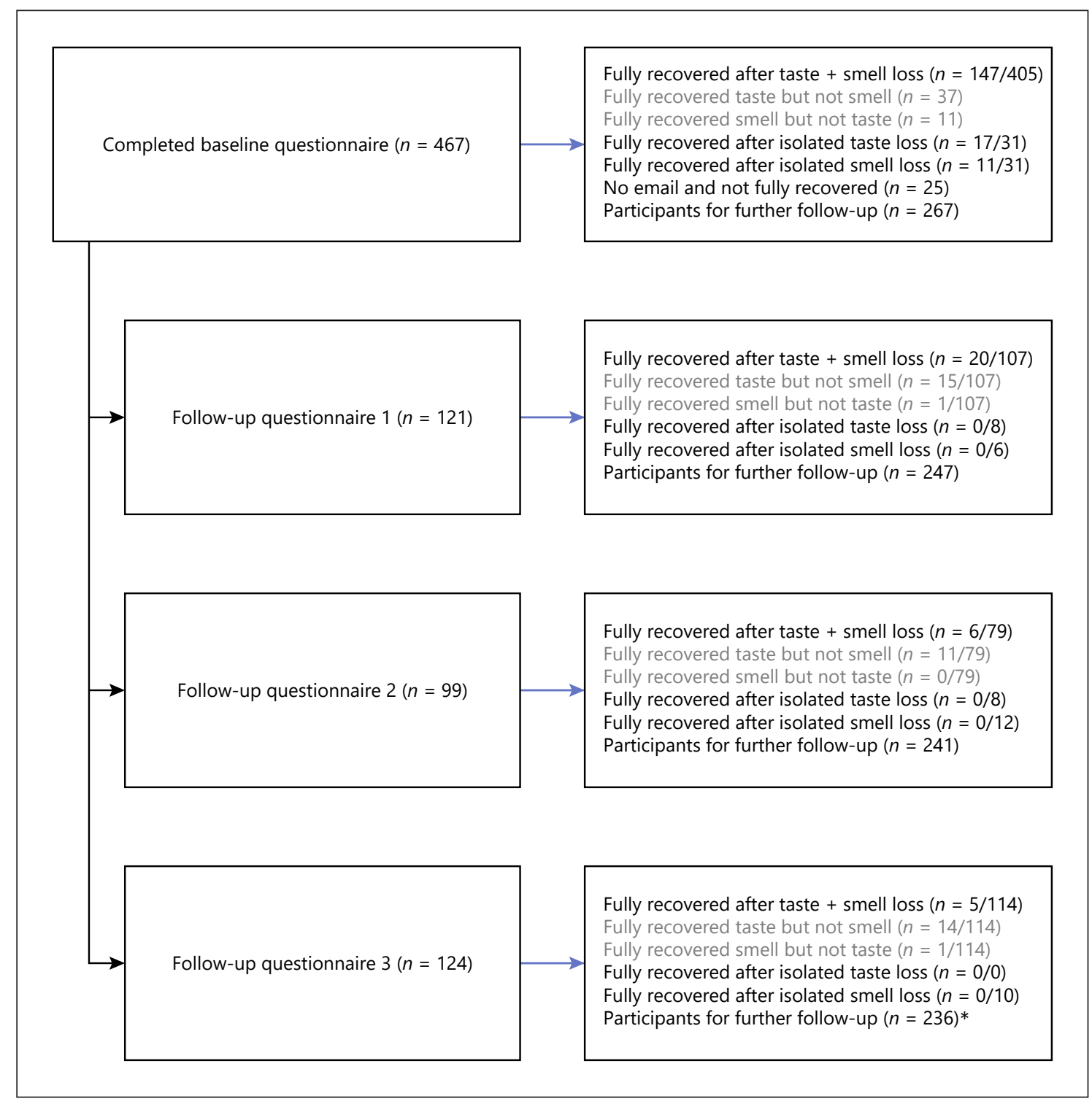

Fig. 1. Flowchart for chemosensory recovery and improvement in follow-up questionnaires. *Among the 236 participants who had not achieved complete sensory recovery, 64 participants had not replied to any of the followup questionnaires.

of COVID-19 was confirmed in Denmark. RT-PCR test-verified COVID-19 was not a criterion for inclusion into the study, as CD was not acknowledged as a possible symptom of COVID-19 by the Danish health-care authorities until May 4, 2020 [20].

The baseline questionnaire included information on subjective olfactory, gustatory, and trigeminal sensory dysfunction, including symptom onset, severity of CD (VAS score, range 0-100), and days until improvement and recovery. Gustatory dysfunction was assessed by asking participants if they had suffered loss of the ability to taste basic tastants (sweet, salty, sour, bitter, or umami), as this reduces the risk of participants misclassifying an olfactory dysfunction as a gustatory dysfunction. Furthermore, data were col- lected on occurrence and timing of other COVID-19 symptoms, medical history, smoking, alcohol consumption, demographics, and earlier episodes of post-viral CD. Data from the first 109 respondents of the baseline questionnaire have previously been published [21].

Participants who had not fully recovered at the time of the baseline questionnaire could enter their email address and give consent to receive follow-up questionnaires. Three rounds of follow-up questionnaires were sent out to these participants with persisting CD in 6-week intervals. The follow-up questionnaire included information on subjective olfactory, gustatory, and trigeminal sensory dysfunction, days until improvement and recovery, and information on any 

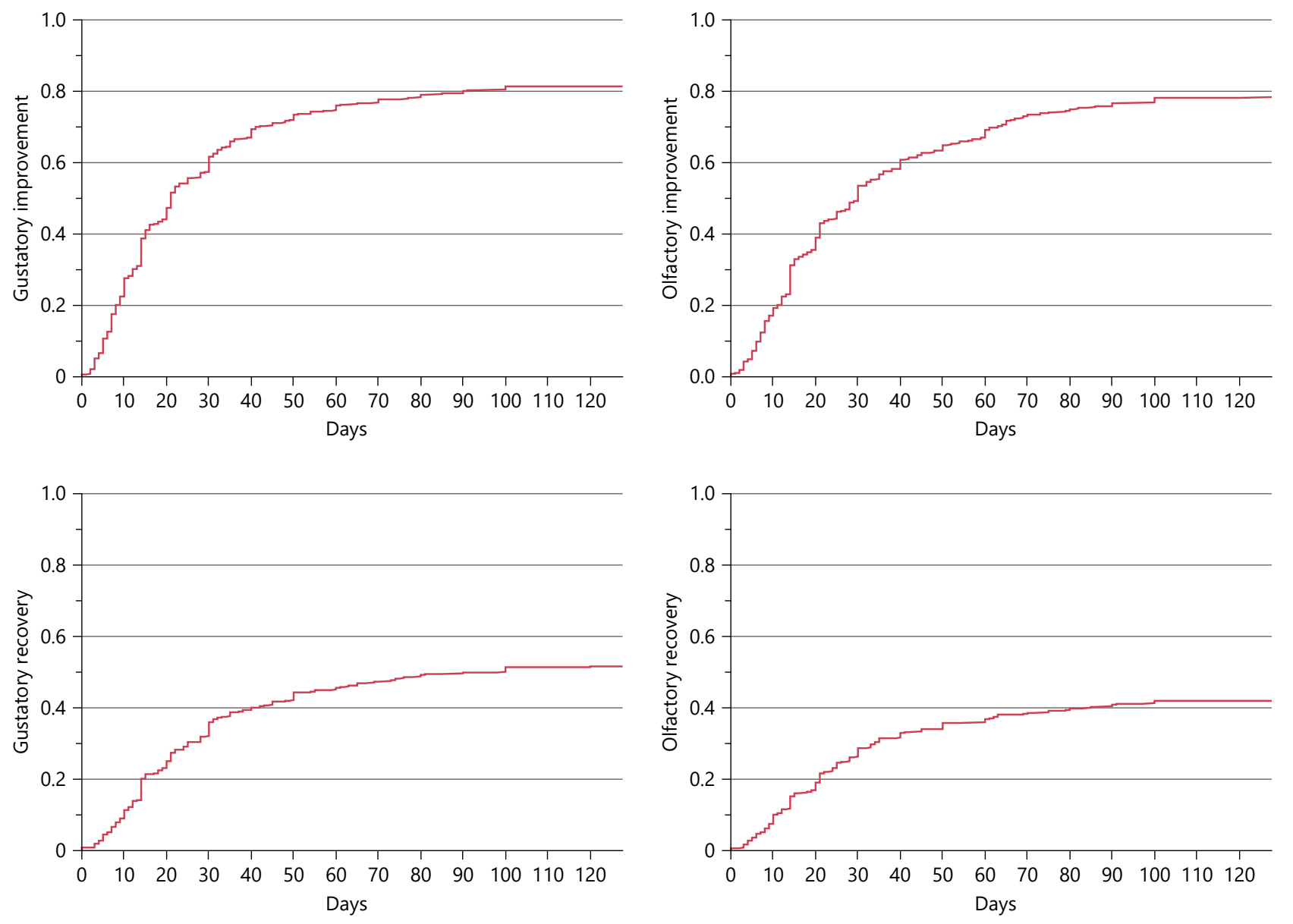

Fig. 2. Chemosensory improvement and recovery during the initial 4 months. Note that complete improvement/recovery ( $y$-axis) is based on the initial chemosensory loss in the baseline questionnaire. In total, 25/467 participants did not choose to add email addresses for further follow-up and 64 participants did not reply to any of the follow-up questionnaires. As such, the longer duration estimates are based on the 203 participants who filled out one or

subsequent SARS-CoV-2 antibody test results. Data collection was initiated on April 22, 2020, and ended on August 28, 2020.

\section{Statistics}

Differences between groups for parametric continuous data were calculated with a 2 -tailed Student's $t$ test, whereas Wilcoxon test was used for nonparametric data. Pearson $\chi^{2}$ test was used for evaluating differences in categorical variables between groups. For parametric data, mean values were calculated and displayed along with 95\% confidence intervals (95\% CI). For nonparametric data, averages were calculated as median values and interquartile ranges were added to ensure an adequate representation of the underlying distributions. However, for some parametric data points, interquartile range values are added to illustrate the underlying distribution of data. more follow-up questionnaires. Although the rates of improvement/recovery may be underestimated after day 65 (duration of chemosensory loss in baseline questionnaire), there seems to be a decrease in recovery rates for both senses after 1-2 months. To ensure sufficient data for the graph, the follow-up time displayed was restricted to the mean follow-up time of the follow-up questionnaire participants (128 days).

\section{Results}

In total, 467 patients completed the baseline questionnaire (demographics are shown in Table 1). Of these, 405 had a combined subjective olfactory and gustatory dysfunction, 31 had an isolated olfactory dysfunction, and 31 had an isolated gustatory dysfunction. The majority of participants chose to enter an email address in the baseline questionnaire $(n=415)$.

The baseline questionnaire was completed on average 2 months after onset of CD (mean 65 days, 95\% CI: 62.6, 68.4). At this time, gustatory function was normalized for 
Table 2. Olfactory and gustatory loss for patients with and without confirmed COVID-19

\begin{tabular}{|c|c|c|c|c|c|c|c|c|}
\hline & \multicolumn{4}{|c|}{ Olfactory dysfunction } & \multicolumn{4}{|c|}{ Gustatory dysfunction } \\
\hline & total & $\begin{array}{l}\text { confirmed } \\
\text { COVID-19 }\end{array}$ & $\begin{array}{l}\text { unknown } \\
\text { COVID-19 }\end{array}$ & difference & total & $\begin{array}{l}\text { confirmed } \\
\text { COVID-19 }\end{array}$ & $\begin{array}{l}\text { unknown } \\
\text { COVID-19 }\end{array}$ & difference \\
\hline Patients & 436 & 188 & 248 & & 436 & 183 & 253 & \\
\hline Gender (female), $n(\%)$ & $323(74.1)$ & $148(78.7)$ & $175(70.6)$ & $p=0.0542\left(\chi^{2}\right)$ & $332(76.1)$ & $148(80.9)$ & $184(72.7)$ & $p=0.0489\left(\chi^{2}\right)$ \\
\hline Age, mean $(95 \% \mathrm{CI})$, years & $43.0(41.7-44.2)$ & $43.0(41.3-44.8)$ & $42.9(41.2-44.7)$ & $\begin{array}{l}p=0.9395 \\
(t \text { test })\end{array}$ & $43.8(42.6-45.1)$ & $43.3(41.5-45.1)$ & $44.2(42.5-46.0)$ & $\begin{array}{l}p=0.4605 \\
(t \text { test })\end{array}$ \\
\hline $\begin{array}{l}\text { Sensory abilities before loss, median } \\
\text { (IQR) }\end{array}$ & $92(81-100)$ & $94.5(84-100)$ & $91(81-100)$ & $\begin{array}{l}p=0.0383 \\
\text { (Wilcoxon) }\end{array}$ & $90(82-100)$ & $92(82-100)$ & $89(81-98)$ & $\begin{array}{l}p=0.0958 \\
\text { (Wilcoxon) }\end{array}$ \\
\hline $\begin{array}{l}\text { Sensory abilities after loss, } \\
\text { median (IQR) }\end{array}$ & $3(0-15)$ & $1(0-8)$ & $5(0-20)$ & $\begin{array}{l}p=0.0002 \\
\text { (Wilcoxon) }\end{array}$ & $11(1-28)$ & $7(0-22)$ & $12(2-35)$ & $\begin{array}{l}p=0.0087 \\
\text { (Wilcoxon) }\end{array}$ \\
\hline $\begin{array}{l}\text { Days to improvement, mean }(n) \\
(95 \% \mathrm{CI})^{*}\end{array}$ & $\begin{array}{l}28.3(n=360) \\
(25.7-30.9)\end{array}$ & $\begin{array}{l}26.9(n=152) \\
(23.3,30.6)\end{array}$ & $\begin{array}{l}29.3(n=208) \\
(25.7,32.9)\end{array}$ & $\begin{array}{l}p=0.3606 \\
(t \text { test })\end{array}$ & $\begin{array}{l}23.5(n=378) \\
(21.3-25.7)\end{array}$ & $\begin{array}{l}22.5(n=160) \\
(19.3-25.6)\end{array}$ & $\begin{array}{l}24.3(n=218) \\
(21.1-27.4)\end{array}$ & $\begin{array}{l}p=0.4198 \\
(t \text { test })\end{array}$ \\
\hline $\begin{array}{l}\text { Days to recovery, mean }(n) \\
(95 \% \mathrm{CI})^{*}\end{array}$ & $\begin{array}{l}27.9(n=191) \\
(24.5-31.2)\end{array}$ & $\begin{array}{l}28.3(n=71) \\
(22.6-34.1)\end{array}$ & $\begin{array}{l}27.6(n=120) \\
(23.5-31.7)\end{array}$ & $\begin{array}{l}p=0.8350 \\
(t \text { test })\end{array}$ & $\begin{array}{l}28.4(n=240) \\
(25.4-31.5)\end{array}$ & $\begin{array}{l}29.3(n=92) \\
(24.0-34.6)\end{array}$ & $\begin{array}{l}27.9(n=148) \\
(24.2-31.6)\end{array}$ & $\begin{array}{l}p=0.6620 \\
(t \text { test })\end{array}$ \\
\hline $\begin{array}{l}\text { Days of follow-up (total), } \\
\text { mean }(n)(95 \% \mathrm{CI})^{*}\end{array}$ & $\begin{array}{l}95.9(n=436) \\
(91.3-100.5)\end{array}$ & $\begin{array}{l}87.4(n=188) \\
(80.4-94.4)\end{array}$ & $\begin{array}{l}102.3(n=248) \\
(33.4-38.8)\end{array}$ & $\begin{array}{l}p=0.0016 \\
(t \text { test })\end{array}$ & $\begin{array}{l}94.0(n=436) \\
(89.5-98.5)\end{array}$ & $\begin{array}{l}87.1(n=183) \\
(80.1-94.1)\end{array}$ & $\begin{array}{l}99.0(n=253) \\
(93.1-104.9)\end{array}$ & $\begin{array}{l}p=0.0111 \\
(t \text { test })\end{array}$ \\
\hline $\begin{array}{l}\text { Days of follow-up (no improvement), } \\
\text { mean }(n)(95 \% \mathrm{CI})^{*}\end{array}$ & $\begin{array}{l}110.5(n=76) \\
(98.8-122.2)\end{array}$ & $\begin{array}{c}102.6(n=36) \\
(85.9-119.2)\end{array}$ & $\begin{array}{l}117.7(n=40) \\
(100.9-134.4)\end{array}$ & $\begin{array}{l}p=0.1992 \\
(t \text { test })\end{array}$ & $\begin{array}{l}114.3(n=58) \\
(101.9-126.7)\end{array}$ & $\begin{array}{c}112.7(n=23) \\
(92.6-132.9)\end{array}$ & $\begin{array}{l}115.4(n=35) \\
(98.8-131.9)\end{array}$ & $\begin{array}{l}p=0.8366 \\
(t \text { test })\end{array}$ \\
\hline $\begin{array}{l}\text { Days of follow-up (no recovery), } \\
\text { mean }(n)(95 \% \mathrm{CI})^{\star}\end{array}$ & $\begin{array}{l}117.9(n=245) \\
(111.8-124.0)\end{array}$ & $\begin{array}{l}105.3(n=117) \\
(96.6-114.1)\end{array}$ & $\begin{array}{l}129.3(n=128) \\
(121.2-137.4)\end{array}$ & $\begin{array}{l}p<0.0001 \\
(t \text { test })\end{array}$ & $\begin{array}{l}116.8(n=196) \\
(109.9-123.7)\end{array}$ & $\begin{array}{c}102.6(n=91) \\
(92.6-112.7)\end{array}$ & $\begin{array}{l}129.1(n=105) \\
(120.0-138.2)\end{array}$ & $\begin{array}{l}p=0.0001 \\
(t \text { test })\end{array}$ \\
\hline
\end{tabular}

$95 \%$ CI, 95\% confidence interval; IQR, interquartile range. * Note that not all patients had improved or recovered after the sensory loss at the time of data collection.

201 participants (46.1\%), while 94 participants (21.6\%) had not yet had any improvement. The recovery from olfactory dysfunction was even slower, as only 169 participants (38.8\%) had recovered completely, while 110 participants (25.2\%) had not experienced any improvement of olfactory function. In total, 163 participants (34.9\%) had recovered from their CD when the baseline questionnaire was completed.

The follow-up questionnaires were sent out to all participants who had not fully recovered $(n=292)$ and had entered their email address in the baseline questionnaire ( $n=267$; missing email address for 25 participants without full recovery). Of these, 203 participants completed one or more follow-up questionnaires (Fig. 1). For these participants, follow-up time increased from 62.3 days (95\% CI: $57.8,66.7$ ) to 128.8 days (95\% CI: $122.8,134.9$ ). During the additional follow-up $(n=203), 66$ participants experienced full gustatory recovery and 33 participants experienced full olfactory recovery (Fig. 2). At the end of the study (mean follow-up of 94.5 days), $82.6 \%$ of participants reported olfactory improvement (360/436) and $86.7 \%$ of participants reported gustatory improvement (378/436), while $43.8 \%$ reported full olfactory recovery $(191 / 436)$ and $55.0 \%$ reported gustatory recovery (240/436) (Table 2).

\section{Possible Prognostic Factors for the Duration of CD}

Age did not significantly differ between the groups who had experienced gustatory improvement (mean difference: -0.47 years [ $95 \% \mathrm{CI}:-3.6$ to 2.7 ], $p=0.7674$ ), gustatory recovery (mean difference: -0.64 years $[95 \%$ CI: -3.1 to 1.8 ], $p=0.6056$ ), olfactory improvement (mean difference: -0.63 years [95\% CI: -3.7 to 2.5], $p=$ 0.6919 ), or olfactory recovery (mean difference: 0.09 years [95\% CI: -2.4 to 2.6], $p=0.9461$ ) (Fig. 3). While females had a higher likelihood of gustatory improvement $\left(\chi^{2}=5.358, p=0.0206\right)$, no gender difference was found in gustatory recovery $\left(\chi^{2}=0.087, p=0.7675\right)$, olfactory improvement $\left(\chi^{2}=0.146, p=0.7020\right)$, or olfactory recovery $\left(\chi^{2}=0.590, p=0.4423\right)$.

Smoking status did not seem to influence gustatory improvement $\left(\chi^{2}=0.431, p=0.8060\right)$; however, a history of smoking (past and current smokers) was associated with lower rates of gustatory recovery $\left(\chi^{2}=13.843, p=\right.$ $0.0078)$. No significant associations were found for olfactory improvement $\left(\chi^{2}=0.802, p=0.9381\right)$ or olfactory recovery $\left(\chi^{2}=5.871, p=0.2090\right)$.

A high subjective severity of initial olfactory dysfunction (visual analog scale [VAS]) was associated with both lower rates of olfactory improvement (mean VAS score difference: 5.6 [95\% CI: 1.2, 9.9], $p=0.0124$ ) and recovery (mean VAS score difference: 14.0 [95\% CI: 9.6, 18.5], $p<$ 0.0001 ). A high subjective severity of initial gustatory dysfunction was associated with lower rates of gustatory recovery (mean VAS score difference: 9.4 [95\% CI: 4.3, $14.6], p=0.0004$ ), while no association was found between subjective severity of initial gustatory dysfunction and gustatory improvement (mean VAS score difference: 0.3 [95\% CI: -5.4 to 6.1 ], $p=0.9052$ ). 


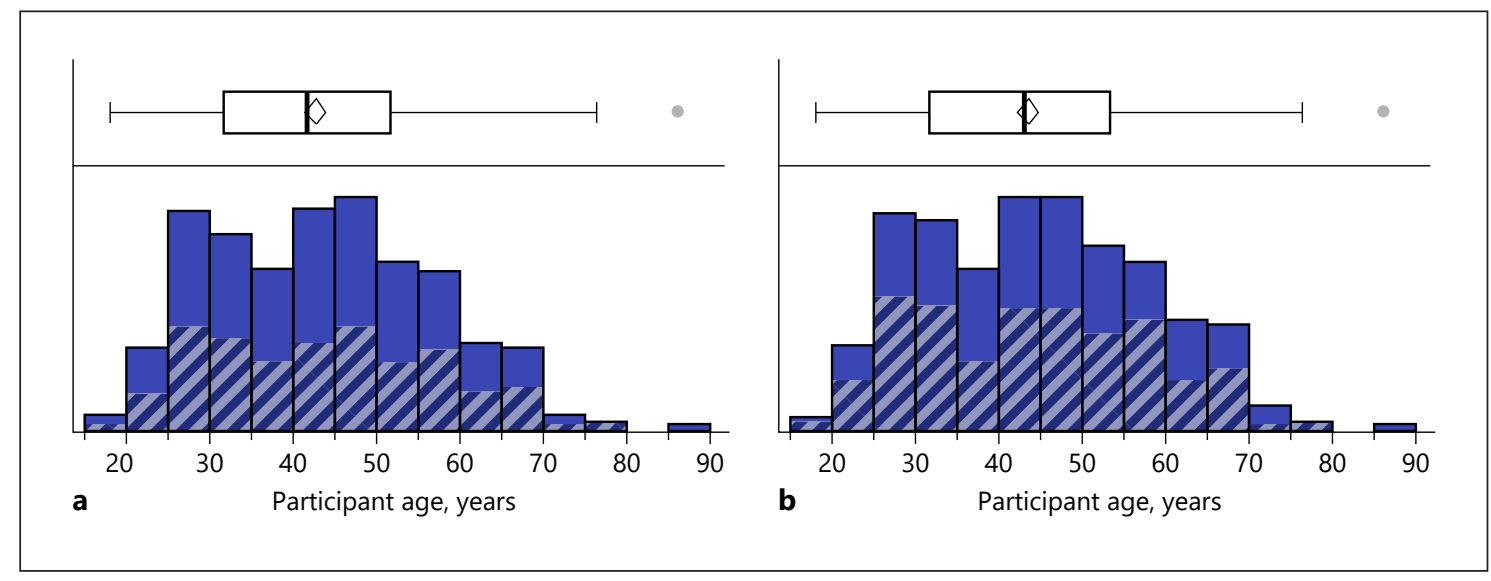

Fig. 3. Distribution of age and recovery. a Age distribution of participants with olfactory dysfunction (full color) and recovery (gray stripes) distribution. b Age distribution of participants with gustatory dysfunction (full color) and recovery (gray stripes) distribution.

\section{Discussion}

\section{Main Findings}

This study examined the severity, improvement, and recovery of subjective CD in a cohort during the SARS$\mathrm{CoV}-2$ pandemic. We found that prolonged subjective olfactory and gustatory dysfunction after COVID-19 is not uncommon. The rate of recovery was most significant during the first month after the initial CD. As shown in Figure 2, rates of improvement and recovery decreased between 1 and 2 months after the onset of CD.

Of the 203 participants who completed one or more follow-up questionnaires (response rate $76 \%$ ), only 33 participants reported full olfactory recovery and 66 participants reported full gustatory recovery. At the end of the study (mean follow-up of 94.5 days), 86.7 and $82.6 \%$ of patients had experienced gustatory and olfactory improvement respectively, and 55.0 and $43.8 \%$ had experienced full gustatory and olfactory recovery.

Young age was not associated with faster improvement or recovery of chemosensory function. While recovery rates did not differ between genders, females were more likely to experience at least some improvement of gustation. A history of smoking was associated with lower rates of gustatory recovery. High subjective severity of initial sensory loss was associated with lower rates of improvement and recovery of olfaction and improvement of gustation.

\section{Comparison with Previous Studies}

Several studies have looked into chemosensory improvement and recovery after COVID-19 with follow-up times of 1-3 months (Table 3). Our data recapitulate the finding of previous studies that the rates of improvement and recovery of chemosensory function are high within the first month after symptom onset.

However, we found relatively low rates of recovery of chemosensory function compared to previous studies, with the mean time to recovery being approximately 4 weeks. This can be partly explained by the fact that our follow-up time was longer than in previously published studies, causing patients with long recovery times to raise the mean. This however does not explain why a comparatively large proportion of our cohort had not recovered at follow-up. This could be due to a selection bias caused by the recruitment method, as it might have favored participants who are more conscious of their sense of smell and taste and may therefore be more sensitive to an impairment of these. Also, the baseline questionnaire was answered on average 2 months after the onset of CD, possibly favoring participants with a persistent dysfunction. As a rapid recovery of $\mathrm{CD}$ is seen in up to two-thirds of patients following COVID-19 [22], the included participants in the current study might mainly reflect the temporal dynamics of CD in patients with prolonged CD.

Our data show that the rates of improvement and recovery become stagnant after about 2 months and only little improvement is seen during 2-4 months of followup. This highlights the potential of subjective $\mathrm{CD}$ as a long-term complication of COVID-19, indicating that 
Table 3. Overview of previous studies [9, 13-16, 35]

\begin{tabular}{|c|c|c|c|c|c|}
\hline Study & $\begin{array}{l}\text { Method of chemosensory } \\
\text { assessment }\end{array}$ & $\begin{array}{l}\text { Population, } n \\
\text { (mean age, } \\
\text { years) }\end{array}$ & $\begin{array}{l}\text { Follow-up } \\
\text { time, mean } \\
\text { (days) }\end{array}$ & $\begin{array}{l}\text { Olfactory function } \\
\text { at follow-up }\end{array}$ & $\begin{array}{l}\text { Gustatory function } \\
\text { at follow-up }\end{array}$ \\
\hline $\begin{array}{l}\text { Brandão Neto } \\
\text { et al. [14] }\end{array}$ & Prospective, interview-based & $655(37.7)$ & 76 & $\begin{array}{l}\text { Full recovery: } 53.8 \% \text {; } \\
\text { partial improvement: } \\
44.7 \% \text {; } \\
\text { no improvement: } 1.4 \%\end{array}$ & $\begin{array}{l}\text { Full recovery: } 68.3 \% \text {; } \\
\text { partial improvement: } \\
27.6 \% \text {; no } \\
\text { improvement: } 4.1 \%\end{array}$ \\
\hline $\begin{array}{l}\text { Otte } \\
\text { et al. [16] }\end{array}$ & $\begin{array}{l}\text { Olfaction was tested using } \\
\text { Sniffin' Sticks (Burghart } \\
\text { Messtechnik GmbH, Wedel, } \\
\text { Germany), and gustation was } \\
\text { tested using taste sprays }\end{array}$ & $91(43.01)$ & 57.9 & $\begin{array}{l}\text { Hyposmia: } 45.1 \% \text {; } \\
\text { normal range: } 53.8 \%\end{array}$ & - \\
\hline $\begin{array}{l}\text { Iannuzzi } \\
\text { et al. [15] }\end{array}$ & $\begin{array}{l}\text { Sniffin' Sticks (Burghart } \\
\text { Messtechnik GmbH, Wedel, } \\
\text { Germany) }\end{array}$ & $30(47.5)$ & $\sim 55$ & $\begin{array}{l}27 \% \text { remained hyposmic; } \\
\text { no patients remained } \\
\text { anosmic }\end{array}$ & \\
\hline
\end{tabular}

Only studies that have looked into improvement and recovery from COVID-19-related chemosensory dysfunction with follow-up times of more than 1 month were included.

further research is needed to determine whether COVID19-related chemosensory loss can be permanent. Furthermore, uncertainties due to subjective assessment of chemosensory function and heterogeneity of study populations complicate the interpretation of current data and need to be addressed by future research.

Young age was not associated with faster improvement or recovery of chemosensory function. Although this is in line with other studies on COVID-19-related olfactory loss $[9,16]$, it is surprising given that young age has previously been shown to be correlated with a better prognosis after post-viral anosmia [17].

Female gender was associated with a higher likelihood of gustatory improvement, while no significant association was found between gender and gustatory recovery nor olfactory improvement/recovery. In all, $65.8 \%$ of par- ticipants were female, indicative of females being more often affected by subjective CD or a selection bias due to the recruitment method, which might favor female participation as females tend to be more conscious of their own health.

The true association between gender and improvement/recovery of chemosensory function after COVID-19 remains controversial, as different studies present contradictory results. Whereas some studies found no significant association [9], other studies have reported that female gender was associated with both better and worse prognosis of regaining normal olfactory function $[13,14]$.

High subjective severity of initial olfactory dysfunction was associated with lower rates of olfactory improvement and recovery. This is in line with findings from 
Amer et al. [13] who found that hyposmic patients recovered faster than anosmic patients. However, caution is warranted in the interpretation of the subjectively rated severity of CD due to the risk of recall bias, which may affect the judgment of patients who were still suffering from $\mathrm{CD}$ when answering the questionnaires.

\section{Consequences for Patients and Health-care System}

Our findings indicate that prolonged CD across all age groups is common after COVID-19 and may constitute a significant burden for both patients and health-care services. Further characterization of CD after COVID-19 is needed in order to identify and treat patients in the best possible way.

\section{Limitations}

Not all participants in the current study had RT-PCRverified COVID-19, and there is thus a risk that some patients with CD not caused by COVID-19 were included in the study population. CD was not acknowledged as a possible symptom of COVID-19 by the Danish health-care authorities until May 4, 2020 [20]. Consequently, participants with isolated CD or only mild secondary symptoms during this period did not meet the requirements for SARS-CoV-2 testing at the time of symptom debut. While this is a clear limitation of the study, Haehner et al. [23] found that the symptom smell loss during this period of the pandemic had a high specificity (97\%) for a positive RT-PCR test for SARS-CoV-2 in a cohort of 500 patients who presented with symptoms of a common cold to a corona testing center. Furthermore, a large symptom-based study on more than 3.2 million UK users of the COVID Symptom Study app found that the predictive ability of loss of smell and taste was higher than fever or persistent cough in the 76.260 users who had been tested for SARSCoV- 2 and that $65 \%$ of individuals with a positive test had complaints of taste and smell loss [3]. Due to the high specificity of CD as a symptom of COVID-19, all patients in this study are interpreted as COVID-19 patients, despite the lack of RT-PCR confirmation. There was no statistically significant difference in the number of days to improvement/recovery for neither olfaction nor gustation between RT-PCR-confirmed cases and non-RT-PCRconfirmed participants. Furthermore, the average age of patients with smell loss in this cohort (mean 43.0 years) does not differ between RT-PCR status but is substantially lower than the normal age span for Danish patients previously seen with olfactory loss (median 57 years) [24].

Participants were recruited through advertisements on social media, national radio, national television, and on flyers in waiting rooms of ENT practitioners and hospital outpatient clinics. The consequential selection bias may cause an overestimation of the prevalence and severity of $\mathrm{CD}$ in the baseline questionnaire. However, this does not account for the prolonged CD in the follow-up questionnaires. As such, this study confirms that $\mathrm{CD}$ after COVID-19 can be prolonged.

Data on olfactory and gustatory function are based on the participants' subjective experience and have not been verified by validated testing or clinical consultation. This holds the inherent risk of over- or underestimating the prevalence and duration of CD due to recall bias as well as misinterpretation of symptoms. Many cases of subjective ageusia cannot be substantiated by validated testing, which is most probably caused by people mistaking a loss of retronasal olfaction for ageusia [24]. However, 1 study showed by means of objective testing that dysgeusia can occur in COVID-19 patients independently of dysosmia and should therefore not be neglected, although the subjective prevalence and duration probably are overestimated by most studies [25]. Subjective assessment of olfaction has been shown to predict abnormal olfactory function in COVID-19 patients [26] and generally correlates well with objective testing in anosmic patients [24].

Loss to follow-up complicates the interpretation of the proportion of patients with a persistent $C D$ at the end of the study period, as participants who regained chemosensory function might be less likely to answer further follow-up questionnaires. The response rate to those was $76 \%$. Females and young people were overrepresented in this cohort, which may be evidence of a selection bias, previously discussed.

\section{Deciphering the Pathogenesis of COVID-19-Related CD}

So far, no consensus has been reached about the pathogenesis of COVID-19-related CD. Data on improvement and recovery rates, as well as possible prognostic factors, may prove valuable in the quest to understand the pathologic mechanisms of COVID-19-related CD. Several plausible mechanisms for the $\mathrm{CD}$ have been proposed.

Early in the pandemic, ACE2, a hormone receptor found in many organs and tissues and required for the entrance of SARS-CoV-2 into the cell, was shown to be expressed in the CNS [27]. This led to the hypothesis that the olfactory bulb may function as an entry point for the SARS-CoV-2 into the CNS $[28,29]$.

Newer studies have since shown that ACE2 is not expressed in olfactory neurons but is expressed by sustentacular cells, olfactory stem cells and pericytes (perivascular 
cells) of the olfactory epithelium [30,31]. Other researchers have proposed that the innate inflammatory response or inflammatory cytokines such as interleukin-6 may play a central role in $\mathrm{CD}[32,33]$. Mueller et al. [34] proposed that younger COVID-19 patients have a higher risk of developing $\mathrm{CD}$, because the youthful immune system reacts faster and more aggressively in the olfactory epithelium and in the process might damage the olfactory neurons.

\section{Conclusion}

The most significant improvement and recovery of chemosensory function was observed within the first month after the initial loss. Rates became stagnant after about 2 months, and only little improvement and recovery was seen after 2-4 months, possibly indicating that lasting and perhaps permanent $\mathrm{CD}$ may be a complication of SARS-CoV-2 infections.

At the end of the study, $86.7 \%$ of participants had experienced gustatory improvement and $82.6 \%$ had experienced olfactory improvement, while $55.0 \%$ had experienced full gustatory recovery and $43.8 \%$ full olfactory recovery. Female gender was associated with faster improvement of gustatory loss, whereas no association between gender and improvement or recovery from olfactory loss was found. High subjective severity of chemosensory loss was associated with lower rates of olfactory and gustatory recovery as well as improvement of olfactory function.

\section{Statement of Ethics}

The study was conducted in accordance with the World Medical Association Declaration of Helsinki. Data were collected after regional approval from the Data Protection Agency. The questionnaire-based design of the study did not require ethics approval according to Danish law (Danish Committee law \$14.2), which was confirmed by the Regional Ethics Committee.

\section{Conflict of Interest Statement}

The authors have no financial disclosures or conflicts of interest.

\section{Funding Sources}

None of the authors received direct funding for this project. The last author wishes to acknowledge research salary funding for other projects from Arla Foods (Viby, Denmark) and the Health Research Fund of Central Denmark Region, as well as research funding from Hans Skouby Foundation and Velux Fonden. The sponsors were not involved in the current study and had no say, roles, or responsibilities in relation to the study, including (but not limited to) the study design, data collection, management, analysis, or decision to publish.

\section{Author Contributions}

J.S.: conceptualization, data analysis, writing - original draft, and writing - review and editing. C.D.J.: conceptualization, data analysis, and writing - review and editing. A.W.F.: conceptualization, data collection, data analysis, writing - original draft, and writing - review and editing.

\section{References}

1 van Doremalen N, Bushmaker T, Morris DH, Holbrook MG, Gamble A, Williamson BN, et al. Aerosol and surface stability of SARSCoV-2 as compared with SARS-CoV-1. N Engl J Med. 2020 Apr 16;382(16):1564-7.

2 World Health Organisation. Coronavirus disease (COVID-19). 2020. [cited 2020 Oct 30] Available from: https://www.who.int/emergencies/diseases/novel-coronavirus-2019/ question-and-answers-hub/q-a-detail/q-acoronaviruses.

3 Menni C, Valdes AM, Freidin MB, Sudre CH, Nguyen LH, Drew DA, et al. Real-time tracking of self-reported symptoms to predict potential COVID-19. Nat Med. 2020 Jul;26(7):1037-40.

4 Wagner T, Shweta F, Murugadoss K, Awasthi S, Venkatakrishnan A, Bade S, et al. Augmented curation of clinical notes from a massive EHR system reveals symptoms of impending COVID-19 diagnosis. Elife. 2020 Jul 7;9:e58277.

5 Agyeman AA, Chin KL, Landersdorfer CB, Liew D, Ofori-Asenso R. Smell and taste dys- function in patients with COVID-19: a systematic review and meta-analysis. Mayo Clin Proc. 2020 Aug;95(8):1621-31.

6 Hajikhani B, Calcagno T, Nasiri MJ, Jamshidi P, Dadashi M, Goudarzi M, et al. Olfactory and gustatory dysfunction in COVID-19 patients: a meta-analysis study. Physiol Rep. 2020 Sep;8(18):e14578.

7 Lechien JR, Chiesa-Estomba CM, De Siati DR, Horoi M, Le Bon SD, Rodriguez A, et al. Olfactory and gustatory dysfunctions as a clinical presentation of mild-to-moderate forms of the coronavirus disease (COVID-19): a multicenter European study. Eur Arch Otorhinolaryngol. 2020 Aug;277(8): 2251-61.

8 Vaira LA, Salzano G, Petrocelli M, Deiana G, Salzano FA, De Riu G. Validation of a selfadministered olfactory and gustatory test for the remotely evaluation of COVID-19 patients in home quarantine. Head Neck. 2020 Jul;42(7):1570-6.
9 Vaira LA, Hopkins C, Petrocelli M, Lechien JR, Chiesa-Estomba CM, Salzano G, et al. Smell and taste recovery in coronavirus disease 2019 patients: a 60-day objective and prospective study. J Laryngol Otol. 2020 Aug; 134(8):703-9.

10 Makaronidis J, Mok J, Balogun N, Magee CG, Omar RZ, Carnemolla A, et al. Seroprevalence of SARS-CoV-2 antibodies in people with an acute loss in their sense of smell and/ or taste in a community-based population in London, UK: an observational cohort study. PLoS Med. 2020 Oct;17(10):e1003358.

11 Parma V, Ohla K, Veldhuizen MG, Niv MY, Kelly CE, Bakke AJ, et al. More than smellCOVID-19 is associated with severe impairment of smell, taste, and chemesthesis. Chem Senses. 2020 Oct 9;45(7):609-22.

12 CDC. Symptoms of Coronavirus. 2020. [Cited 2020 Oct 30]. Available from: https://www. cdc.gov/coronavirus/2019-ncov/symptomstesting/symptoms.html.
Sustained COVID-19 Chemosensory Dysfunction
ORL 2021;83:209-218 
13 Amer MA, Elsherif HS, Abdel-Hamid AS, Elzayat S. Early recovery patterns of olfactory disorders in COVID-19 patients; a clinical cohort study. Am J Otolaryngol. 2020 Nov-Dec; 41(6):102725.

14 Brandão Neto D, Fornazieri MA, Dib C, Di Francesco RC, Doty RL, Voegels RL, et al. Chemosensory dysfunction in COVID-19: prevalences, recovery rates, and clinical associations on a large Brazilian sample. Otolaryngol Head Neck Surg. 2020 Sep 1: 194599820954825.

15 Iannuzzi L, Salzo AE, Angarano G, Palmieri VO, Portincasa P, Saracino A, et al. Gaining back what is lost: recovering the sense of smell in mild to moderate patients after COVID- 19. Chem Senses. 2020 Dec 5;45(9):875-81.

16 Otte MS, Eckel HNC, Poluschkin L, Klussmann JP, Luers JC. Olfactory dysfunction in patients after recovering from COVID-19. Acta Otolaryngol. 2020 Dec;140(12): 1032-5.

17 Reden J, Mueller A, Mueller C, Konstantinidis I, Frasnelli J, Landis BN, et al. Recovery of olfactory function following closed head injury or infections of the upper respiratory tract. Arch Otolaryngol Head Neck Surg. 2006 Mar; 132(3):265-9.

18 Hopkins C, Surda P, Whitehead E, Kumar BN. Early recovery following new onset anosmia during the COVID-19 pandemic - an observational cohort study. J of Otolaryngol Head Neck Surg. 2020 May 4;49(1):26.

19 Harris PA, Taylor R, Thielke R, Payne J, Gonzalez N, Conde JG. Research electronic data capture (REDCap): a metadata-driven methodology and workflow process for providing translational research informatics support. J Biomed Inform. 2009 Apr;42(2):377-81.
20 Sundhedsstyrelsen. Retningslinjer for håndtering af COVID-19 i sundhedsvæsenet. [cited 2020 Apr 1]. Available from: https:// www.sst.dk/-/media/Udgivelser/2020/Corona/Retningslinjer-marts/Retningslinje-COVID-19.ashx?la $=$ da\& hash $=84942068$ EA3916 2A0B8E26A6AAFD6CC256276F14.

21 Fjaeldstad AW. Prolonged complaints of chemosensory loss after COVID-19. Dan Med J. 2020;67(8):A05200340.

22 Konstantinidis I, Delides A, Tsakiropoulou E, Maragoudakis P, Sapounas S, Tsiodras S. Short-term follow-up of self-isolated COVID-19 patients with smell and taste dysfunction in Greece: two phenotypes of recovery. ORL J Otorhinolaryngol Relat Spec. 2020; 82(6):295-303

23 Haehner A, Draf J, Dräger S, de With K, Hummel T. Predictive value of sudden olfactory loss in the diagnosis of COVID-19. ORL J Otorhinolaryngol Relat Spec. 2020;82(4): $175-80$.

24 Fjaeldstad A, Stankovic J, Onat M, Stankevice D, Ovesen T. Patients and experiences from the first Danish flavour clinic. Dan Med J. 2020;67(4):1.

25 Vaira LA, Lechien JR, Salzano G, Salzano FA, Maglitto F, Saussez S, et al. Gustatory dysfunction: a highly specific and smell-independent symptom of COVID-19. Indian J Otolaryngol Head Neck Surg. 2020 Sep 30:1-3.

26 Prajapati DP, Shahrvini B, MacDonald BV, Crawford KL, Lechner M, DeConde AS, et al. Association of subjective olfactory dysfunction and 12-item odor identification testing in ambulatory COVID-19 patients. Int Forum Allergy Rhinol. 2020;10(11):1209-17.

27 Baig AM, Sanders EC. Potential neuroinvasive pathways of SARS-CoV-2: deciphering the spectrum of neurological deficit seen in coronavirus disease-2019 (COVID-19). J Med Virol. 2020 Oct;92(10):1845-57.
28 Bougakov D, Podell K, Goldberg E. Multiple neuroinvasive pathways in COVID-19. Mol Neurobiol. 2020 Sep 29:1-12.

29 Butowt R, Bilinska K. SARS-CoV-2: olfaction, brain infection, and the urgent need for clinical samples allowing earlier virus detection. ACS Chem Neurosci. 2020 May 6;11(9): $1200-3$.

30 Bilinska K, Jakubowska P, Von Bartheld CS, Butowt R. Expression of the SARS-CoV-2 entry proteins, ACE2 and TMPRSS2, in cells of the olfactory epithelium: identification of cell types and trends with age. ACS Chem Neurosci. 2020 Jun 3;11(11):1555-62.

31 Brann DH, Tsukahara T, Weinreb C, Lipovsek M, Van den Berge K, Gong B, et al. Non-neuronal expression of SARS-CoV-2 entry genes in the olfactory system suggests mechanisms underlying COVID-19-associated anosmia. Sci Adv. 2020 Jul 31;6(31): eabc5801.

32 Cazzolla AP, Lovero R, Lo Muzio L, Testa NF, Schirinzi A, Palmieri G, et al. Taste and smell disorders in COVID-19 patients: role of interleukin-6. ACS Chem Neurosci. 2020 Sep 2; 11(17):2774-81.

33 Rodriguez S, Cao L, Rickenbacher GT, Benz EG, Magdamo C, Ramirez Gomez LA, et al. Innate immune signaling in the olfactory epithelium reduces odorant receptor levels: modeling transient smell loss in COVID-19 patients. medRxiv. 2020 Jun 16: 2020.06.14.20131128.

34 Mueller AL, McNamara MS, Sinclair DA. Why does COVID-19 disproportionately affect older people?. Aging. 2020 May 29; 12(10):9959-81.

35 Chiesa-Estomba CM, Lechien JR, Radulesco T, Michel J, Sowerby LJ, Hopkins C, et al. Patterns of smell recovery in 751 patients affected by the COVID-19 outbreak. Eur J Neurol. 2020 Jul;16. http://dx.doi.org/10.1111/ene.14440. 